\title{
The Role of Adsorbed Ions during Electrocatalysis in Ionic
}

\section{Liquids}

\author{
Andinet Ejigu and Darren A. Walsh* \\ School of Chemistry, The University of Nottingham, Nottingham NG7 2RD, UK \\ *darren.walsh@nottingham.ac.uk;
}

Tel: 0044115 8467495; Fax: 00441159513562 


\begin{abstract}
The effects of electrode-adsorbate interactions on electrocatalysis at $\mathrm{Pt}$ in ionic liquids are described. The ionic liquids are diethylmethylammonium trifluoromethanesulfonate, [dema][TfO], dimethylethylammonium trifluoromethanesulfonate, [dmea][TfO], and diethylmethylammonium bis(trifluoromethanesulfonyl)imide, [dema][Tf $2 \mathrm{~N}]$. Electrochemical analysis indicates that a monolayer of hydrogen adsorbs onto Pt during potential cycling in [dema $][[\mathrm{TfO}]$ and $[\mathrm{dmea}][\mathrm{TfO}]$. In addition, a pre-peak is observed at lower potentials than that of the main oxidation peak during $\mathrm{CO}$ oxidation in the [TfO $]^{-}$-based liquids. In contrast, hydrogen does not adsorb onto Pt during potential cycling in [dema] $\left[\mathrm{Tf}_{2} \mathrm{~N}\right]$ and no pre-peak is observed during $\mathrm{CO}$ oxidation. By displacing adsorbed ions on $\mathrm{Pt}$ surfaces with $\mathrm{CO}$ at a range of potentials, and measuring the charge passed during ion displacement, the potentials of zero total charge of $\mathrm{Pt}$ in [dema][TfO] and [dmea][TfO] were measured as $271 \pm 9 \mathrm{mV}$ and $289 \pm 10 \mathrm{mV} v s$. RHE, respectively. CO displacement experiments also indicate that the $\left[\mathrm{Tf}_{2} \mathrm{~N}\right]^{-}$ion is bound to the Pt surface at potentials above $-0.2 \mathrm{~V}$ and the implications of ion adsorption on electrocatalysis of the $\mathrm{CO}$ oxidation reaction and $\mathrm{O}_{2}$ reduction reaction in the protic ionic liquids are discussed.
\end{abstract}

Keywords: ionic liquid; CO displacement; electrocatalysis; potential of zero charge; ion adsorption 


\section{Introduction}

The development of more efficient fuel cells, electrolyzers and metal-air batteries depends on the development of new and improved electrocatalysts for reactions such as the hydrogen evolution reaction (HER), hydrogen oxidation reaction (HOR), CO oxidation reaction (COOR), oxygen evolution reaction (OER), and oxygen reduction reaction (ORR). While the search for new electrocatalysts was once an empirical trial-and-error endeavor, the emergence of the field of "surface electrocatalysis" has put electrocatalyst development on a sound scientific basis and led to major advances, not only in our understanding of electrocatalysis, but also in electrochemical energy conversion. ${ }^{1,2}$ In the case of fuel cell electrocatalysis, work by Marković, Nørskov, Adzic, Feliu and others, which combines electrochemical measurements at well-defined surfaces with surface analysis and theory, has illustrated the importance of electrode-ion interactions during electrocatalysis. ${ }^{3-9}$ During the ORR at Pt, for example, adsorption of (bi)sulfate, ${ }^{10}$ halide, ${ }^{11}$ phosphate, ${ }^{12}$ and oxide ${ }^{13}$ ions onto catalyst sites affects the electrochemical reaction rate. The sluggishness of the ORR near its thermodynamic potential, which drastically reduces the performance of proton exchange membrane fuel cells, is now primarily attributed to the strong adsorption of oxides (often described as $\mathrm{OH}_{\text {ads }}$ ) on catalytic Pt sites above $1.0 \mathrm{~V}$ and state-of-the-art ORR electrocatalysts have been designed to optimise the $\mathrm{Pt}-\mathrm{OH}_{\mathrm{ads}}$ binding strength. ${ }^{14-17}$

Room temperature ionic liquids (RTILs) are materials that are composed entirely of ions and liquid below $100{ }^{\circ} \mathrm{C} .{ }^{18}$ RTILs often exhibit a range of useful properties, including high thermal and chemical stabilities and wide potential windows. ${ }^{19,20}$ Due to such favorable properties, RTILs are being used in a wide variety of electrochemical applications, ranging from fundamental studies of mass and charge transport dynamics ${ }^{21-25}$ to the development of new electrochemical energy conversion and storage devices. ${ }^{26-32}$ However, while some work has been aimed at elucidating the structure of the electrode/RTIL interface as a 
function of the applied potential, ${ }^{33-35}$ most researchers interested in using RTILs for electrochemistry have focused on relationships between bulk liquid properties, such as thermal stability, viscosity and conductivity, and electrochemical behavior. The effects of ion adsorption on electrocatalytic processes in RTILs have not been studied in detail thus far and no electrocatalysts have been designed specifically for use in RTILs. If devices such as ionic liquid-based fuel cells are to compete with conventional proton exchange membrane fuel cells, as has been proposed, ${ }^{28}$ it is likely that "task-specific" electrocatalysts and ionic liquids will be required and their development depends on us developing a thorough understanding of electrocatalysis in RTILs.

In this paper, we describe the effects of ion adsorption on electrocatalysis of the COOR and ORR in protic ionic liquids (PILs), a class of RTILs formed by addition of a Brønsted acid to a Brønsted base. The PILs are diethylmethylammonium trifluoromethanesulfonate, [dema][TfO], dimethylethylammonium trifluoromethanesulfonate, [dmea][TfO] and diethylmethylammonium bis(trifluoromethanesulfonyl)imide, [dema][Tf $\left.{ }_{2} \mathrm{~N}\right]$ (Scheme 1). These materials have been selected as they represent some of the most promising PILs for use in non-humidified, ionic liquid-based fuel cells. ${ }^{29,36}$ In addition, we have chosen to study surface electrocatalysis in these PILs at polycrystalline Pt surfaces as the PIL-based fuel cells developed thus far have contained polycrystalline Pt electrocatalysts. ${ }^{29,30}$

We begin by first describing the surface electrochemistry of Pt in the blank PILs. Our data suggests that adsorption of a monolayer of hydrogen onto Pt can occur during potential<smiles>CC[NH+](C)CC</smiles><smiles>O=S(=O)([O-])C(F)(F)F</smiles><smiles>CC[NH+](C)C</smiles><smiles>CC[NH+](C)CC</smiles>

Scheme 1. Structure of (left to right) [dema][TfO], [dmea][TfO], and [dema][Tf $\left.{ }_{2} N\right]$ 
cycling in $[$ dema $][\mathrm{TfO}]$ and $[\mathrm{dmea}][\mathrm{TfO}]$ but not in $[\mathrm{dema}]\left[\mathrm{Tf}_{2} \mathrm{~N}\right]$. Similarly, we demonstrate that a pre-peak appears at lower potentials than that of the main oxidation peak during the $\mathrm{CO}$ oxidation in $[\mathrm{dema}][\mathrm{TfO}]$ and $[\mathrm{dmea}][\mathrm{TfO}]$ but not in $[\mathrm{dema}]\left[\mathrm{Tf}_{2} \mathrm{~N}\right]$. While the appearance of a pre-peak during electrocatalytic $\mathrm{CO}$ oxidation has been observed previously in aqueous media, ${ }^{37}$ this is the first time that such a peak has been observed in ionic liquids and we propose that its appearance in the [TfO]-based liquids is due to co-adsorption of $\mathrm{H}$ and $\mathrm{CO}$ onto the electrode surface.

In this paper, we also describe the first measurements of the potential of zero total charge (pztc) in ionic liquids using $\mathrm{CO}$ displacement experiments, in which neutral $\mathrm{CO}$ molecules displace adsorbed ions and the charge transferred during ion desorption is measured..$^{6,38,39}$ The pztc is the potential at which anions begin to predominate over cations on the electrode surface and its measurement can yield extremely useful information about electrode-adsorbate interactions and their effects on electrocatalysis. ${ }^{37,40}$ As we discuss below, the use of $\mathrm{CO}$ displacement experiments indicate that in $[$ dema $]\left[\mathrm{Tf}_{2} \mathrm{~N}\right]$ the Pt surface is covered predominantly by adsorbed $\left[\mathrm{Tf}_{2} \mathrm{~N}\right]^{-}$anions to low potentials, which appears to hinder $\mathrm{H}$ adsorption onto the $\mathrm{Pt}$ surface during potential cycling in the PIL. Adsorption of the $\left[\mathrm{Tf}_{2} \mathrm{~N}\right]^{-}$anion onto the Pt surface also helps explain the absence of a pre-peak during $\mathrm{CO}$ oxidation in $[$ dema $]\left[\mathrm{Tf}_{2} \mathrm{~N}\right]$. Finally, we propose that adsorption of the $\left[\mathrm{Tf}_{2} \mathrm{~N}\right]^{-}$anion onto $\mathrm{Pt}$ surfaces may be partly responsible for the high ORR overpotential at Pt in $[\mathrm{dema}]\left[\mathrm{Tf}_{2} \mathrm{~N}\right]$ relative to that in the $[\mathrm{TfO}]^{-}$-based liquids.

\section{Experimental Section}

Materials and Apparatus. All chemicals were obtained from Sigma-Aldrich or Alfa Aesar and were used as received. PILs were prepared and characterized according to published procedures ${ }^{36,41}$ and were dried by stirring at $70{ }^{\circ} \mathrm{C}$ under vacuum $\left(6 \times 10^{-2}\right.$ mbar $)$ 
for $48 \mathrm{hrs}$ prior to use. After drying, the residual $\mathrm{H}_{2} \mathrm{O}$ contents of the PILs were measured using a coulometric Karl Fischer apparatus (Mitsubishi CA100) and were 0.024 wt. \%, 0.019 wt. $\%$, and 0.045 wt. $\%$ for [dema][TfO], [dmea][TfO] and [dema][Tf $\left.{ }_{2} \mathrm{~N}\right]$, respectively. Electrochemical measurements were performed using a model $760 \mathrm{C}$ potentiostat $(\mathrm{CH}$ Instruments, Austin, TX). Rotating disk electrode (RDE) voltammetry, cyclic voltammetry and linear sweep voltammetry were carried out using a $5 \mathrm{~mm}$ diameter Pt disk electrode attached to a model MSR rotator shaft (Pine Instruments, Durham, NC). Electrochemical measurements were performed at $45^{\circ} \mathrm{C}$ by immersing the entire electrochemical cell into an oil bath and temperature control was afforded by a K-type thermocouple.

Electrochemical Measurements. A three-electrode electrochemical cell containing the Pt disk electrode, a Pt flag counter electrode $\left(\right.$ area $=1.6 \mathrm{~cm}^{2}$ ), and a reference electrode was used for electrochemical measurements. As reference electrode, a "reversible hydrogen electrode," RHE, was used which consisted of a $1 \mathrm{~cm}^{2}$ Pt black flag immersed in the PIL of interest while $\mathrm{H}_{2}$ flowed over the surface at a constant rate, as described by Watanabe. ${ }^{29}$ Alternatively, a self-contained RHE containing Pt black and a $\mathrm{H}_{2}$ gas source (Gaskatel, Kassel, Germany) was used. ${ }^{42}$ The potentials of both reference electrodes were the same to within experimental error and, using each reference electrode, the onset potential for $\mathrm{H}_{2}$ oxidation at Pt was $0.0 \mathrm{~V}$ in the $[\mathrm{TfO}]^{-}$-based liquids and $0.2 \mathrm{~V}$ in $[\mathrm{dema}]\left[\mathrm{Tf}_{2} \mathrm{~N}\right]$, in agreement with the data published by Friesen ${ }^{43}$ and Watanabe. ${ }^{29} \mathrm{An} \mathrm{Ag} / \mathrm{Ag}^{+}$reference electrode was used for $\mathrm{CO}$ electrochemistry and was constructed by immersing an $\mathrm{Ag}$ wire in $10 \mathrm{mM}[\mathrm{Ag}][\mathrm{TfO}]$ in the ionic liquid of interest. The potential of the $\mathrm{Ag} / \mathrm{Ag}^{+}$electrode was calibrated against that of the RHE and, for consistency, all potentials are reported versus the RHE. Prior to use, the Pt electrode was polished using an aqueous suspension of $0.05 \mu \mathrm{m}$ alumina (Buehler, Lake Bluff, Illinois) on a felt polishing pad, sonicated in an ultrasonic bath in a small amount of water, rinsed thoroughly with deionised water, and dried under $\mathrm{N}_{2}$. 
CO oxidation in each PIL was studied by first bubbling CO into the PIL of interest for 40 min while the Pt electrode potential was held at $0.1 \mathrm{~V}$ (unless otherwise indicated). A blanket of $\mathrm{CO}$ was maintained above the PIL when performing $\mathrm{CO}$ oxidation measurements. CO displacement experiments were performed by first purging the PIL with Ar for 40 min. Complete removal of $\mathrm{CO}$ from each PIL was then verified by performing linear sweep voltammetry in the $\mathrm{CO}$ oxidation potential range. $\mathrm{CO}$ was then introduced into the Ar-purged PIL at various potentials while the electrode was rotated at $1000 \mathrm{rpm}$ and the current was recorded as a function of time. Measurements in $\mathrm{O}_{2}$-containing PILs were performed by saturating the PILs with $\mathrm{O}_{2}$ for 40 min by vigorously bubbling $\mathrm{O}_{2}$ through the liquid and a blanket of $\mathrm{O}_{2}$ was maintained above the PIL during measurements.

\section{Results and Discussion}

Cyclic Voltammetry of Pt in PILs. Figures 1A-1C show CVs recorded at a stationary Pt electrode in CO-free and CO-saturated [dema][TfO], [dmea][TfO] and [dema][Tf $\left.{ }_{2} \mathrm{~N}\right]$, respectively. The main features observed during potential cycling in PILs such as these have been described previously; ${ }^{41,43,44} \mathrm{H}_{2}$ oxidation during the positive sweep (red line, feature A1), is followed by surface oxidation (red line, feature A2). During the reverse sweep, surface oxides are reduced (red line, feature $\mathrm{C} 1$ ) and $\mathrm{H}_{2}$ evolution occurs near $0.0 \mathrm{~V}$ (red line, feature C2). While the electrochemical response observed in $[\mathrm{dema}]\left[\mathrm{Tf}_{2} \mathrm{~N}\right]$ was broadly similar to that observed in the $[\mathrm{TfO}]^{-}$-based liquids, a significant difference in the kinetics of the C2/A1 couple is visible upon moving from the $[\mathrm{TfO}]^{-}$-based liquids to [dema $]\left[\mathrm{Tf}_{2} \mathrm{~N}\right]$. For example, the peak-to-peak separation, $\Delta E_{\mathrm{p}}$, of the $\mathrm{C} 2 / \mathrm{A} 1$ couple in the [dema][TfO] was about $250 \mathrm{mV}$, while that in [dema] $\left[\mathrm{Tf}_{2} \mathrm{~N}\right]$ was about $900 \mathrm{mV}$ at $50 \mathrm{mV} \mathrm{s}^{-1}$, demonstrating that $\mathrm{H}_{2}$ oxidation is particularly sluggish in [dema] $\left[\mathrm{Tf}_{2} \mathrm{~N}\right]$, as has been observed previously. ${ }^{29}$

Before discussing the responses obtained in the CO-saturated PILs, it is interesting to 

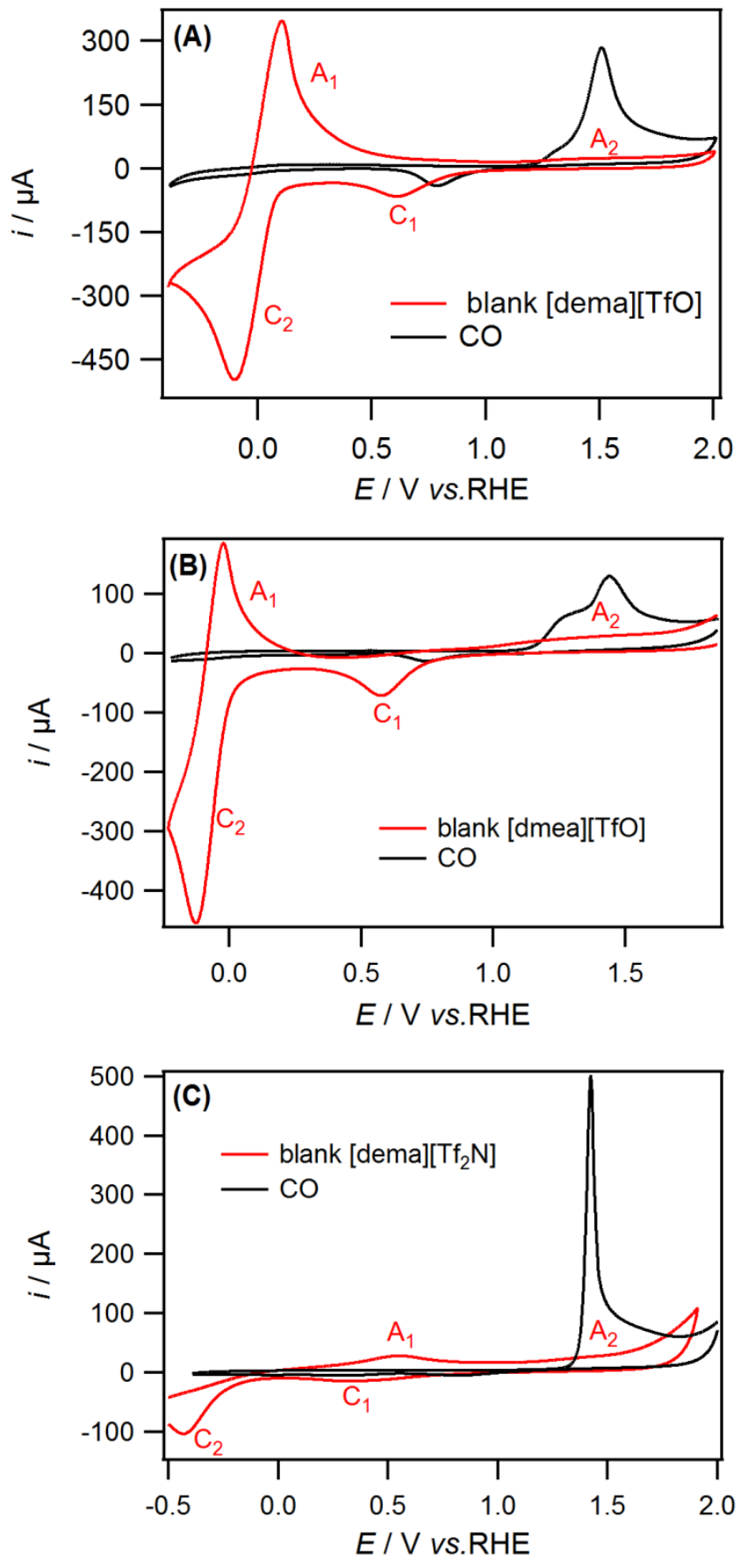

Figure 1. CVS recorded at a $5 \mathrm{~mm}$ diameter Pt electrode at $50 \mathrm{mV} \mathrm{s}{ }^{-1}$ at $45^{\circ} \mathrm{C}$ in (A) blank (red line) and CO-saturated (black line) [dema][TfO] by sweeping the potential between -0.4V (initial potential) and $2.0 \mathrm{~V}$, (B) blank (red line) and CO-saturated (black line) [dmea][TfO] by sweeping the potential between $-0.23 \mathrm{~V}$ (initial potential) and $1.85 \mathrm{~V}$, and

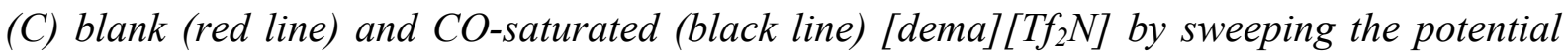
between - $0.5 \mathrm{~V}$ (initial potential) and $2.0 \mathrm{~V}$. The red labels (A1, C2, etc.) correspond to the features observed in the blank PILs. The water content of [dema][TfO], [dmea][TfO], and [dema][Tf $2 \mathrm{~N}]$ was 0.024 wt. \%, 0.019 wt. \%, and 0.045 wt. \%, respectively. 

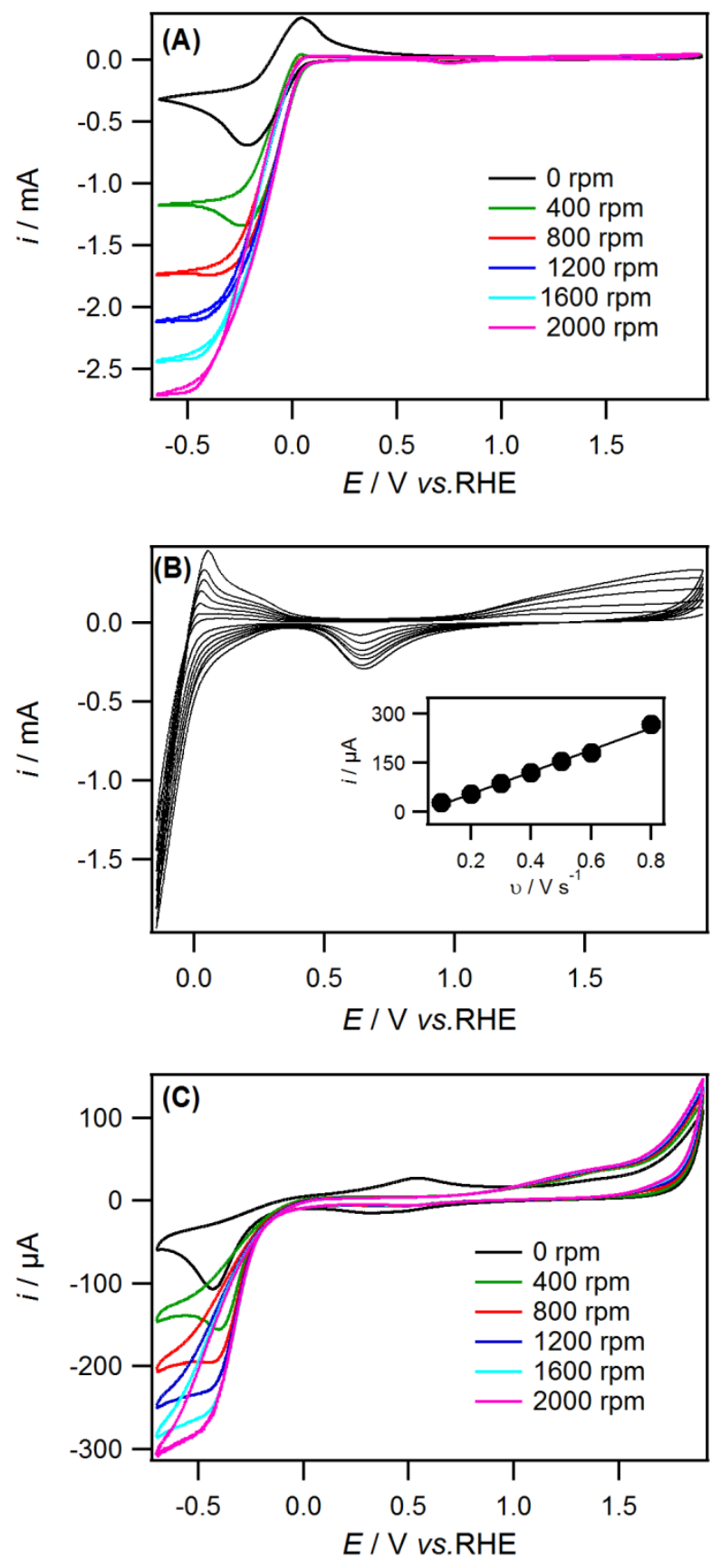

Figure 2. (A) RDE voltammograms obtained at a $5 \mathrm{~mm}$ diameter Pt disk at $50 \mathrm{mV} \mathrm{s}^{-1}$ at the indicated rotation rates in [dema][TfO] by cycling the potential between -0.65 V (initial potential) and $2.0 \mathrm{~V}$. (B) RDE voltammograms obtained at a $5 \mathrm{~mm}$ diameter Pt disk at 2000 rpm as the potential was scanned at (from bottom to top) 100, 200, 300, 400, 500, 600 and $800 \mathrm{mV} \mathrm{s}^{-1}$ from -0.15 $\mathrm{V}$ to $1.95 \mathrm{~V}$ in [dema][TfO]. The inset shows the plot of the absolute current, $i$, at $0.1 \mathrm{~V} v$ s. the potential scan rate, $v$. (C) RDE voltammograms obtained at a 5 $\mathrm{mm}$ diameter Pt disk at $50 \mathrm{mV} \mathrm{s}^{-1}$ at the indicated rotation rates in [dema][Tf $\left.{ }_{2} \mathrm{~N}\right]$ by cycling the potential between $-0.7 \mathrm{~V}$ (initial potential) and $1.9 \mathrm{~V}$ 
compare the voltammetric behaviour of Pt in the blank PILs when the electrode was rotated (Figure 2). When the electrode was rotated in [dema][TfO] (Figure 2A), $\mathrm{H}_{2}$ formed below 0.0 $\mathrm{V}$ was swept away from electrode surface and the $\mathrm{H}_{2}$ oxidation peak near $0.1 \mathrm{~V}$ was suppressed (Figure 2A). However, even at $2000 \mathrm{rpm}$, the Pt voltammetric peaks did not disappear completely and a voltammogram reminiscent of that observed during potential cycling of $\mathrm{Pt}$ in aqueous $\mathrm{H}_{2} \mathrm{SO}_{4}$ was obtained (Figure 2B). ${ }^{45}$ Waves associated with $\mathrm{Pt}$ oxidation and reduction, each of which increased in size with increasing potential scan rate, $v$, were visible at $2000 \mathrm{rpm}$. The potential region between $0.0 \mathrm{~V}$ and $0.3 \mathrm{~V}$ in Figure 2B is also particularly interesting; during the cathodic sweep, a reduction wave, which increased in height with increasing $v$, was observed between $0.3 \mathrm{~V}$ and $0.0 \mathrm{~V}$ and this was followed by bulk $\mathrm{H}_{2}$ evolution at potentials below $0.0 \mathrm{~V}$. During the positive sweep, an oxidation wave was observed between $0.0 \mathrm{~V}$ and $0.3 \mathrm{~V}$ and the inset of Figure $2 \mathrm{~B}$ shows that the height of the oxidation wave between $0.0 \mathrm{~V}$ and $0.3 \mathrm{~V}$ was directly proportional to $v$. These reduction and oxidation features are similar to those obtained during underpotential deposition and stripping of $\mathrm{H}$ atoms from $\mathrm{Pt}$ surfaces during potential cycling in $\mathrm{H}_{2} \mathrm{SO}_{4}{ }^{45}$ Therefore, these data suggest that hydrogen had adsorbed onto the electrode surface during potential cycling in [dema][TfO] presumably due to reduction of the ionic liquid cation and/or the trace water dissolved within the ionic liquid, which after 48 hrs drying under vacuum persisted in the ionic liquid at a concentration of 0.024 wt. $\%{ }^{41}$ For comparison, Figure $2 \mathrm{C}$ shows the responses obtained as the electrode was rotated in $[\mathrm{dema}]\left[\mathrm{Tf}_{2} \mathrm{~N}\right]$. In this case, hydrogen adsorption onto the electrode appeared not to occur; the hydrogen oxidation peak disappeared completely as $\mathrm{H}_{2}$ was swept away from the electrode surface and, as the potential was scanned from negative to positive potentials at the rotating electrode, negligible current flowed until oxidation of the Pt surface occurred near 1.0 V (Figure 2C). 
Further evidence for hydrogen adsorption onto the electrode surface during potential cycling in [dema][TfO] is obtained by measuring the average charge under the oxidation peaks in Figure 2B, which was $226 \mu \mathrm{C} \mathrm{cm}^{-2}$. This value compares very well with the value of $210 \mu \mathrm{C} \mathrm{cm}^{-2}$ expected for oxidation of a complete monolayer of adsorbed $\mathrm{H}$ atoms from a $\mathrm{Pt}$ surface. ${ }^{46}$ We note that underpotential $\mathrm{H}$ adsorption onto Pt electrodes has been observed previously in imidazolium-based ionic liquids by Compton and co-workers during the voltammetry of benzoic acid and that the adsorbed hydrogen oxidation charge also corresponded to that expected for oxidation of complete monolayer of $\mathrm{H}$ atoms. ${ }^{47}$ In our study, very similar behavior was observed in [dmea][TfO] as was observed in [dema][TfO] and integration of oxidation peaks between $0.0 \mathrm{~V}$ and $0.3 \mathrm{~V}$ at a rotating Pt electrode in [dmea][TfO] yielded a charge of $221 \mu \mathrm{C} \mathrm{cm}^{-2}$, which again is close to that expected for oxidation of an adsorbed layer of $\mathrm{H}$ atoms from the Pt surface. That $\mathrm{H}$ adsorption had occurred in both of the $[\mathrm{TfO}]^{-}$-based liquids but not in $[\mathrm{dema}]\left[\mathrm{Tf}_{2} \mathrm{~N}\right]$ suggests that the $\left[\mathrm{Tf}_{2} \mathrm{~N}\right]^{-}$ anion may have blocked adsorption sites on the Pt surface, a phenomenon that is explored further in the following sections.

Returning to the data in Figure 1, it is clear that the A1 and C2 features (red lines near $0.0 \mathrm{~V}$ ) were completely suppressed as $\mathrm{CO}$ was introduced into each PIL and adsorbed onto the Pt surface (black lines in Figure 1). As the potential was scanned positive in CO-saturated [dema][TfO] and [dmea][TfO], negligible current flowed until approximately $1.1 \mathrm{~V}$ (Figure 1A and $1 \mathrm{~B}$ ) when $\mathrm{CO}$ oxidation began. $\mathrm{CO}$ oxidation has been studied previously in ionic liquids and found to coincide with oxidation of the Pt surface according to the LangmuirHinshelwood mechanism for $\mathrm{CO}$ oxidation by adsorbed oxides (which form from trace water oxidation in the ionic liquid). ${ }^{48,49}$ It is interesting to note that an oxidation pre-peak is visible prior to the main $\mathrm{CO}$ oxidation peak in Figures $1 \mathrm{~A}$ and $1 \mathrm{~B}$. In addition, while the $\mathrm{CV}$ recorded in $[$ dema $]\left[\mathrm{Tf}_{2} \mathrm{~N}\right]$ showed a sharp $\mathrm{CO}$ oxidation peak at the same potential as that of 
the main $\mathrm{CO}$ oxidation peaks in $[\mathrm{dema}][\mathrm{TfO}]$ and $[\mathrm{dmea}][\mathrm{TfO}]$, it is perhaps most notable for the absence of any pre-peak for CO oxidation (Figure 1C).

A pre-peak has been observed previously during $\mathrm{CO}$ oxidation in aqueous electrolytes $^{37,50}$ and there are two main theories to describe its appearance. The most popular explanation is that some adsorbed $\mathrm{H}\left(\mathrm{H}_{\mathrm{ads}}\right)$ forms at the same time as adsorbed $\mathrm{CO}\left(\mathrm{CO}_{\mathrm{ads}}\right)$ during pre-adsorption of $\mathrm{CO}$ onto the Pt surface and oxidation of $\mathrm{H}_{\mathrm{ads}}$ at low potentials then frees up some Pt sites allowing $\mathrm{OH}_{\text {ads }}$ nucleation and early (or so-called "pre-ignition") $\mathrm{CO}_{\mathrm{ads}}$ oxidation. $^{37,51}$ An alternative explanation by Marković proposes that weakly and strongly adsorbed $\mathrm{CO}_{\mathrm{ads}}$ layers are formed on the Pt surface during deposition of $\mathrm{CO}_{\text {ads. }}{ }^{52}$ Increased lateral repulsion within the weakly adsorbed layer allows the formation of $\mathrm{OH}_{\text {ads }}$ at low potentials, which results in early onset oxidation of $\mathrm{CO}_{\mathrm{ads}}$. After oxidation of the weakly adsorbed $\mathrm{CO}_{a d s}$, the remaining $\mathrm{CO}_{\text {ads }}$ layer relaxes forming a less-compressed, strongly-bound layer of $\mathrm{CO}_{\mathrm{ads}}$ that is more resistant to $\mathrm{OH}_{\mathrm{ads}}$ nucleation on the surface and this stronglyadsorbed layer is oxidized in the main CO oxidation peak. However, as Kucernak has pointed out, ${ }^{37}$ Marković's explanation does not preclude the possibility of co-adsorption of $\mathrm{H}_{\mathrm{ads}}$ with $\mathrm{CO}_{\text {ads }}$ onto the Pt surface.

Considering that $\mathrm{H}_{\mathrm{ads}}$ formed at low potentials on $\mathrm{Pt}$, and a pre-peak was observed during $\mathrm{CO}$ oxidation, in the $\left[_{\mathrm{TfO}}\right]^{-}$-based PILs, whereas neither effect was apparent in $[\mathrm{dema}]\left[\mathrm{Tf}_{2} \mathrm{~N}\right]$, it appears that co-adsorbed hydrogen may indeed have played a role in early onset of $\mathrm{CO}$ oxidation in the [TfO]-based PILs. Further evidence that adsorbed hydrogen plays a role during $\mathrm{CO}$ oxidation can be obtained by considering the data shown in Figure 3, which shows voltammograms recorded during oxidation of $\mathrm{CO}_{\mathrm{ads}}$ layers in $\mathrm{CO}$-free [dema][TfO]. In this case, the adsorbed CO layers were formed at two different potentials, one where hydrogen is expected to adsorb onto the Pt surface $(0.1 \mathrm{~V})$ 


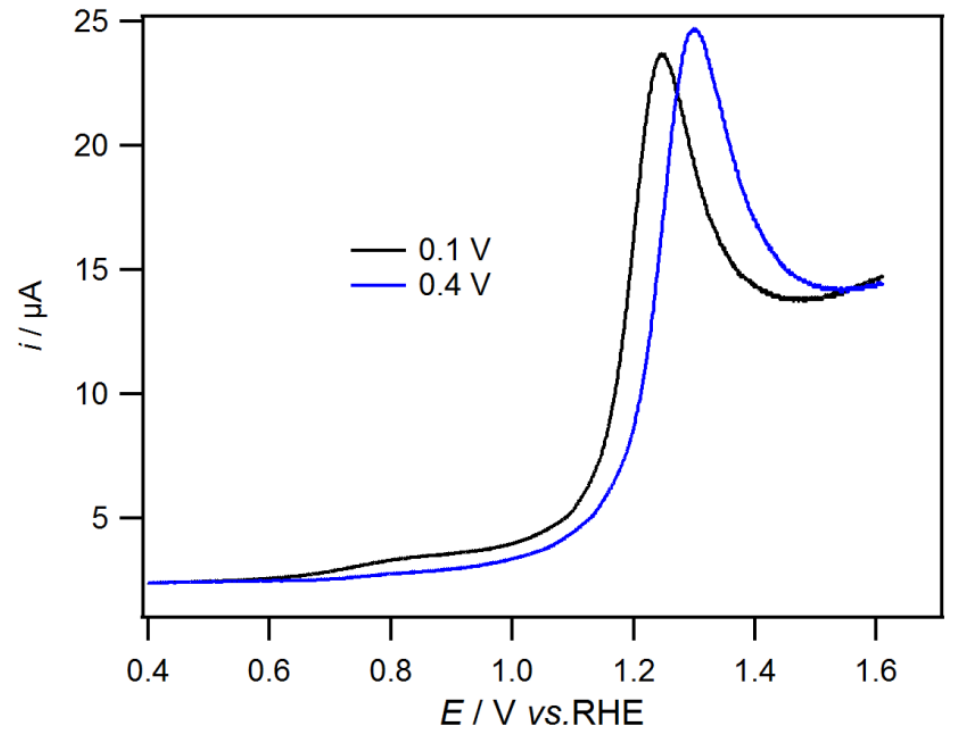

Figure 3. Linear sweep voltammograms recorded at a $5 \mathrm{~mm}$ Pt disk electrode in [dema][TfO] by sweeping the potential from $0.4 \mathrm{~V}$ to 1.6 at $50 \mathrm{mV} \mathrm{s}^{-1}$. The CO was preadsorbed on the Pt surface by holding the potential at (black line) $0.1 \mathrm{~V}$ and (blue line) $0.4 \mathrm{~V}$ in CO-saturated [dema][TfO] for $10 \mathrm{~min}$, after which the liquid was purged of CO by bubbling with Ar for 40 min.

and one where adsorbed hydrogen should be unstable on the Pt surface $(0.4 \mathrm{~V})$. No pre-peak was observed during $\mathrm{CO}$ oxidation of the $\mathrm{CO}_{\text {ads }}$ layer that was deposited at $0.4 \mathrm{~V}$ supporting our suggestion that co-adsorption of $\mathrm{H}$ with $\mathrm{CO}$ may be responsible for the existence of the $\mathrm{CO}$ oxidation pre-peak in the $\left[\mathrm{TfO}^{-}\right.$-based liquids. It is also interesting to note the differences in the oxidation potentials of the $\mathrm{CO}$ monolayers formed at the different deposition potentials. The monolayer formed at $0.4 \mathrm{~V}$ was oxidized at a more positive potential than that deposited at $0.1 \mathrm{~V}$, indicating that the layer formed at $0.4 \mathrm{~V}$ was more stable against oxidation. This observation could be explained by considering the origin the $\mathrm{CO}$ oxidation pre-peak. If the $\mathrm{CO}_{\text {ads }}$ layer formed at $0.1 \mathrm{~V}$ contained adsorbed $\mathrm{H}$ that was oxidized during the potential sweep, resulting in the early onset of $\mathrm{CO}$ oxidation, it is likely that the $\mathrm{CO}$ layer left behind after loss of this adsorbed $\mathrm{H}$ is less resistant to $\mathrm{OH}_{\text {ads }}$ nucleation and $\mathrm{CO}_{\mathrm{ads}}$ oxidation than the layer formed at $0.4 \mathrm{~V}$, which contained no such readily-oxidized 
components. When considering the appearance and absence of the CO-oxidation pre-peak in these liquids, one could, of course, argue that it is possible that the $\mathrm{CO}$ layers formed in the $\left[\mathrm{Tf}_{2} \mathrm{~N}\right]^{-}$- and $[\mathrm{TfO}]^{-}$-containing liquids (at the same potential) differ in how the CO adsorbs to the surface (the adsorption modes of $\mathrm{CO}$ onto $\mathrm{Pt}$ in liquids such as these have not been studied $^{48}$ ), irrespective of whether adsorbed $\mathrm{H}$ forms, and that differences in the structures of the CO layers formed in different liquids are responsible for the appearance or absence of the pre-peak. One could also argue that the $\mathrm{CO}$ adlayers formed in [dema][TfO] at $0.1 \mathrm{~V}$ and 0.4 $\mathrm{V}$ differ in terms of their bonding modes, rather than in the inclusion of $\mathrm{H}$ into the layer, and that these differences are responsible for the appearance or absence of the pre-peak. While future work will no doubt focus on Pt-CO bonding in ionic liquids, such a coincidence appears unlikely and it does appear that adsorbed $\mathrm{H}$ did play a part in causing the appearance of the $\mathrm{CO}$ oxidation pre-peak in the [TfO]-based PILs, as has also been proposed for aqueous systems. $^{37,51}$

It is also interesting to note that there is a significant difference between the responses obtained during $\mathrm{CO}$ oxidation in CO-saturated [dema][TfO] and CO-free [dema][TfO] (compare Figures 1 and 3). In CO-saturated [dema][TfO] (Figure 1A), the bulk CO oxidation peak potential was at about $1.5 \mathrm{~V}$ whereas, in $\mathrm{CO}$-free [dema][TfO], it was at about $1.2 \mathrm{~V}$ (Figure 3, black line). The CO oxidation pre-peak, while less significant than that in Figure 1A, also appeared at a much lower potential in the CO-free PIL than during bulk CO oxidation (0.8 V in CO-free [dema][TfO] $v$ s. $c a .1 .3 \mathrm{~V}$ in CO-saturated [dema][TfO]). The large difference in the oxidation potential can be attributed to effective mass transport and strong adsorption of $\mathrm{CO}$ to the Pt surface during bulk (or "continuous") $\mathrm{CO}$ oxidation; as $\mathrm{CO}$ is supplied continuously to the Pt surface, it blocks potential oxide adsorption sites, suppressing $\mathrm{CO}$ oxidation and pushing the $\mathrm{CO}$ oxidation potential higher than in the $\mathrm{CO}$-free PIL. ${ }^{52,53}$ Efficient transport of CO to the Pt surface in the CO-saturated PIL also meant that 
the second and subsequent cycles observed the CO-saturated PILs (Figure 1) were the same as the first cycles. Investigations of $\mathrm{CO}$ oxidation under such conditions (i.e., continuous $\mathrm{CO}$ oxidation in a CO-saturated solution) are useful as they impact on the understanding of catalysis in fuel cells where continuous supply of reactants to the catalyst surface occurs. In particular, $\mathrm{CO}$ is likely to be fed continuously to fuel cell anodes as a contaminant in $\mathrm{H}_{2}$ fuel supplies. $^{54}$

Displacement of Ions from Electrodes by CO. The potential of zero charge (pzc) is the potential at which the charge on the metal side of an electrode/electrolyte interface is zero and is one of the most important parameters in surface electrocatalysis. ${ }^{40}$ A number of studies have been devoted to determining pzcs of metal electrodes in ionic liquids, typically using measurements of the differential capacitance as a function of the applied potential. ${ }^{34,35,55}$ Kornyshev recently introduced a formula for the diffuse double layer capacitance in RTILs, ${ }^{56}$ which predicts either camel-shaped curves or bell-shaped curves depending on the compressibility of the RTIL and both curve types (as well as U-shaped curves) have been observed in RTILs. ${ }^{57-59}$ Complications arise, however, when the cation and anion sizes are different and the pzc can shift away from the capacitance maximum (in the case of bellshaped curves). ${ }^{60}$

In measurements of the pzc, complications can also arise when specific adsorption of ions onto the electrode surface occurs because charge can be contributed to the surface by the adsorbing ions. To account for such charge transfer effects, Frumkin and Petrii defined two different potentials of zero charge: the potential of zero free charge (pzfc) is that at which the truly free, excess charge density on the electrode is zero and the potential of zero total charge (pztc) is that at which the charge density on the electrode plus any charge transferred during ion adsorption is zero. ${ }^{61}$ In the absence of any specific adsorption (i.e., at an ideally 
polarizable interface), pzfc and pztc coincide, but this is not usually the case at Pt electrodes, and the only experimentally accessible value is the pztc. ${ }^{62}$

It has been proposed that one can accurately measure the pztc by measuring the charge passed when neutral CO molecules displace adsorbed ions from an electrode surface. ${ }^{6,38,63}$ In such "CO-displacement" experiments, a potential is applied to the electrode, CO is introduced to the cell, and strongly adsorbed CO displaces adsorbed anions and cations from the electrode surface according to equations 1 and 2:

$\mathrm{Pt}$-cation $+\mathrm{CO} \rightarrow \mathrm{Pt}-\mathrm{CO}+(\text { cation })^{+}+\mathrm{e}^{-}$

Pt-anion $+\mathrm{CO}+\mathrm{e}^{-} \rightarrow \mathrm{Pt}-\mathrm{CO}+(\text { anion })^{-}$

As no net charge is considered to flow during $\mathrm{CO}$ adsorption, the measured displacement charge density depends on the quantity (and charge) of displaced ions. Assuming that no other reactions occur during $\mathrm{CO}$ displacement and the charge density remaining on the surface is negligible, one can directly measure the pztc by determining the potential at which the displacement charge density versus potential curve crosses zero. ${ }^{40}$ However, it is notable that such an approach has not been demonstrated in ionic liquids to date but, if it were possible to use such a method, a direct measurement of the pztc in ionic liquids could be possible, which avoids the complications associated with differential capacitance measurements.

To examine whether $\mathrm{CO}$ could displace adsorbed ions from the electrode/ionic liquid interface, $\mathrm{CO}$ was dosed into an electrochemical cell containing a polished Pt electrode and CO-free $[$ dema $][\mathrm{TfO}]$ at a range of potentials and the resulting current-time transients are shown in Figure 4A. The curves are offset from the zero current axis for clarity. Before CO was introduced to the cell, the current reached a negligible steady-state background value. When $\mathrm{CO}$ was introduced into the cell and adsorbed to the Pt surface held at potentials $\leq$ 
$0.251 \mathrm{~V}$ (top 3 curves in Figure 4A), the transient current increase was positive indicating that $\mathrm{CO}$ displaced cations from the Pt surface at low potentials according to Equation 1. At potentials $\geq 0.281 \mathrm{~V}$, the current increased transiently in the negative direction indicating that anions were expelled from the surface according to Equation 2 (bottom 3 curves in
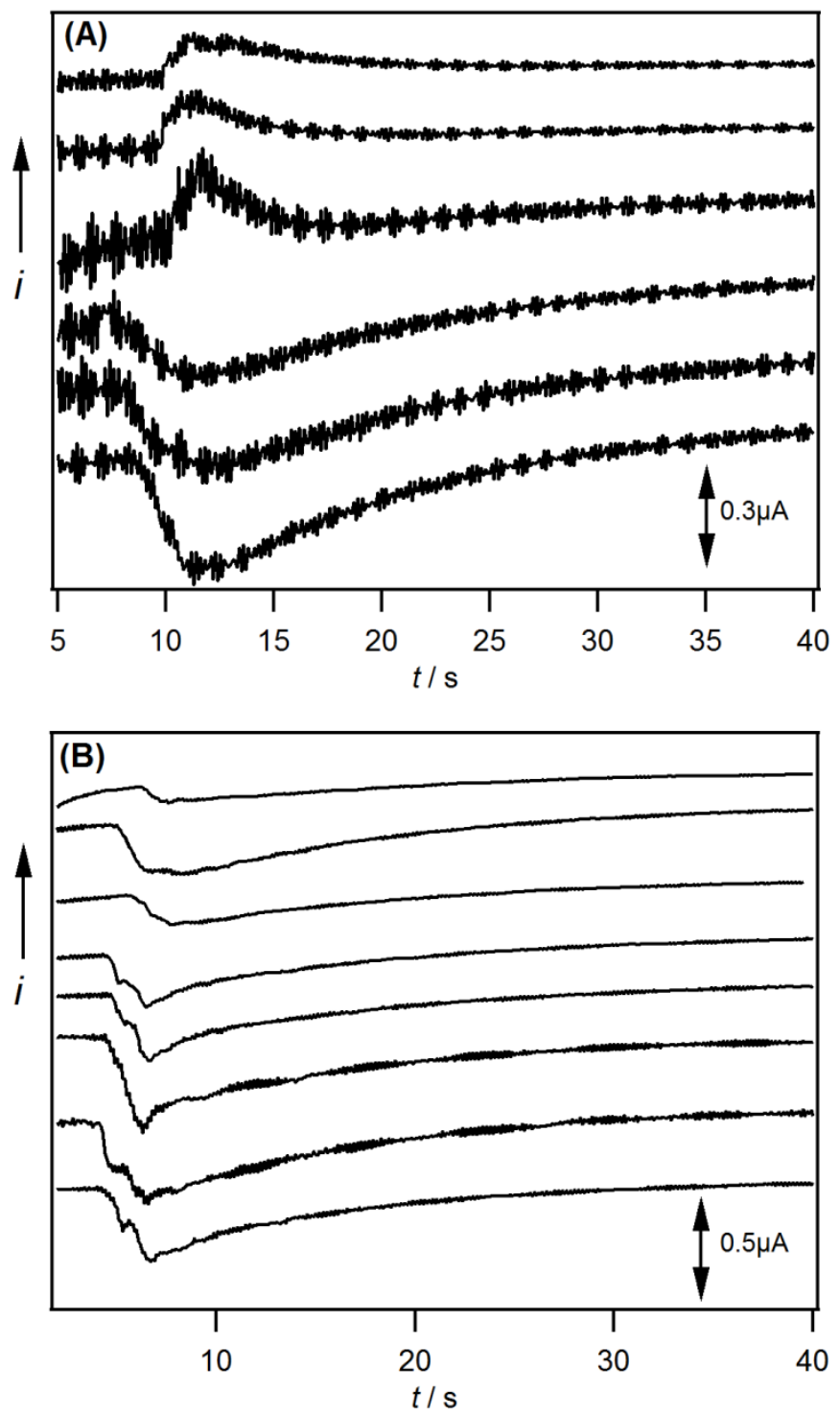

Figure 4. Current-time transients recorded during $C O$ displacement experiments in $(A)$ [dema][TfO] and (B) [dema][Tf $2 \mathrm{~N}]$. CO was introduced into the cell after the background current reached a negligible, steady-state value. In A, the applied potentials were (from top to bottom) $0.211,0.241,0.251,0.281,0.321$ and $0.346 \mathrm{~V}$. In $\mathrm{B}$, the applied potentials were (from top to bottom) $-0.2,-0.16,-0.14,-0.1,-0.05,0.0,0.1$, and $0.2 \mathrm{~V}$. 
Figure 4A). In all cases, the current decayed to zero at longer times due the increasing $\mathrm{CO}_{\mathrm{ads}}$ coverage on the Pt surface. The behavior observed in the PIL is similar to that observed by Mayrhofer et al. using aqueous media where the displacement current increased positively and negatively as $\mathrm{CO}$ adsorbed onto a Pt electrode held at potentials either side of the pztc. ${ }^{40}$ In Mayrhofer's study, the displaced cations were identified as underpotential-deposited hydrogen and the adsorbed anions were identified as $\mathrm{OH}^{-}$and $\mathrm{ClO}_{4}{ }^{-}$ions. In our study, the displacement current that flowed at low potentials was likely due to the removal of adsorbed $\mathrm{H}$ (see Figure 2B), releasing protons that may have been accommodated by the ionic liquid anion yielding the free $\mathrm{TfOH}$ acid. The displacement current that flowed at potentials $\geq 0.281$ $\mathrm{V}$ could represent loss of oxide ions from the surface (we recently showed that adsorbed oxide species form in these PILs due to trace water dissociation ${ }^{42}$ ) or it could represent displacement of the PIL's [TfO] $]^{-}$anions from the Pt surface. Deposition of $\mathrm{OH}_{\mathrm{ads}}$ at such low potentials in aqueous systems has been suggested previously ${ }^{37}$ but the absence of an appreciable $\mathrm{CO}$ oxidation current at such low potentials in [dema][TfO] (Figure 1A and 3) suggests that significant amounts of adsorbed oxide species were not present at the $\mathrm{Pt} /[\mathrm{dema}][\mathrm{TfO}]$ interface at potentials as low as $0.281 \mathrm{~V}$ and that the desorbing anions were predominantly $[\mathrm{TfO}]^{-}$ions.

Figure 5A shows a graph of the displacement charge versus the applied potential in [dema][TfO]. Extrapolation of the displacement charge to zero gives a value of $271 \pm 9 \mathrm{mV}$ for the pztc of Pt in [dema][TfO]. The pztc of Pt in [dema][TfO] has not been measured previously but this value compares to measured pztc values for $\mathrm{Pt}$ of $285 \mathrm{mV}$ in $0.1 \mathrm{M}$ $\mathrm{HClO}_{4}{ }^{40}$ and $234 \mathrm{mV}$ and $269 \mathrm{mV}$ in $0.5 \mathrm{M} \mathrm{H}_{2} \mathrm{SO}_{4}{ }^{37,63}$ The $\mathrm{CO}$ displacement behaviour observed in [dmea][TfO] was similar to that observed in [dema][TfO] and analysis of the displacement charge-potential curve for [dmea][TfO] (Figures 5B) gives a pztc value of $289 \pm$ 

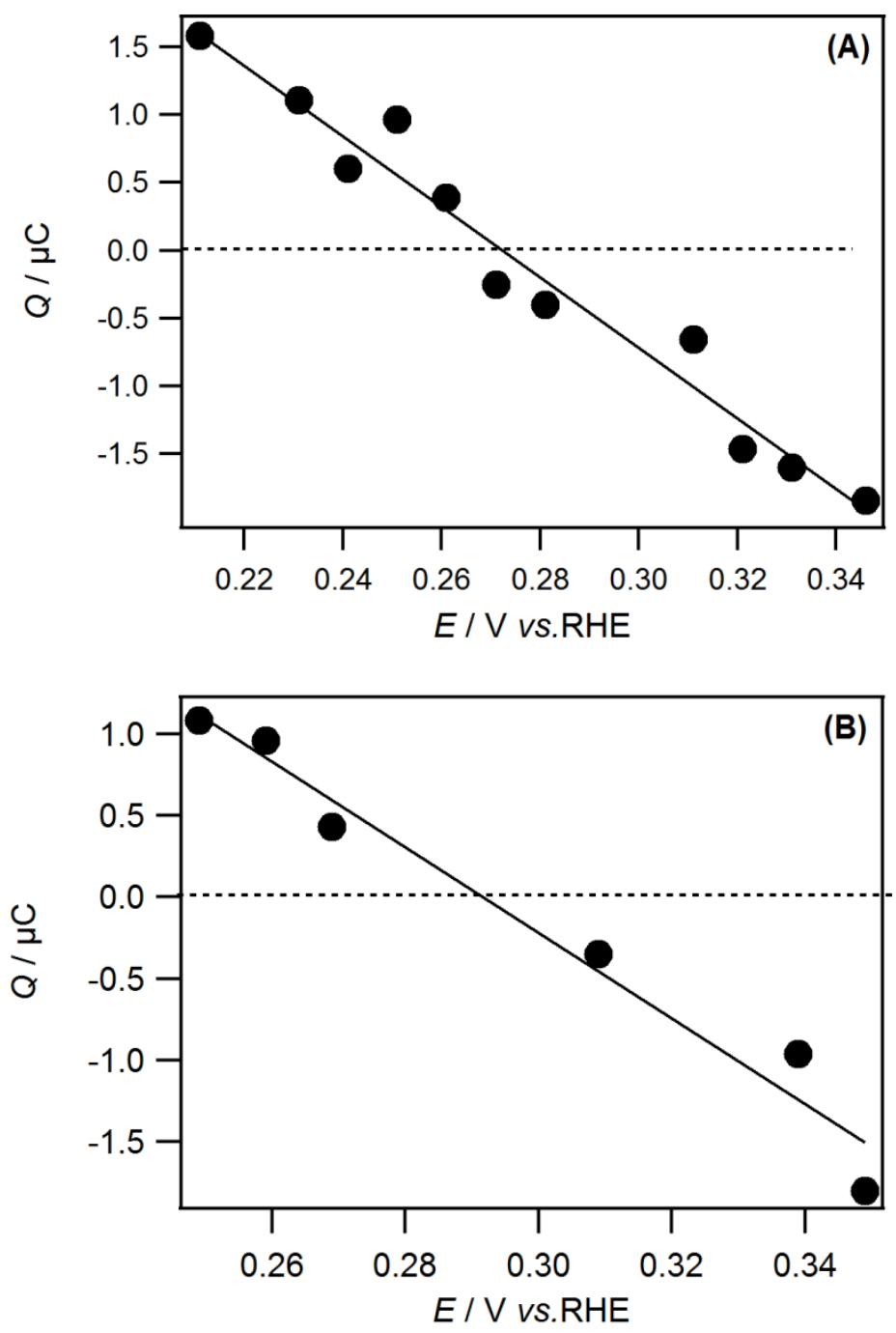

Figure 5. Integrated charge under the CO-displacement peak versus the applied potential in (A) $[$ dema][TfO] and (B) [dmea][TfO]. The pztc is the potential at which the line crosses the zero current axis.

$10 \mathrm{mV}$. The Pt oxidation potential was similar in [dmea][TfO] to that in [dema][TfO] (Figure $1 \mathrm{~A}$ and $1 \mathrm{~B})$ suggesting that the anions desorbing at the potentials on the right hand side of Figure 5B were also predominantly [TfO $]^{-}$anions rather than oxide anions.

The current-time transients measured upon introducing $\mathrm{CO}$ to the cell containing [dema][Tf $\left.{ }_{2} \mathrm{~N}\right]$ (Figure 4B) differed from those observed in the [TfO]-based liquids. At all potentials studied (the available negative potential limit in $\mathrm{CO}$ displacement experiments in [dema] $\left[\mathrm{Tf}_{2} \mathrm{~N}\right]$ was limited by the onset of $\mathrm{H}_{2}$ evolution - see Figure 2C), a 
transient increase in negative current was observed as $\mathrm{CO}$ reached the Pt surface. This suggests that $\left[\mathrm{Tf}_{2} \mathrm{~N}\right]$ anions were displaced from the surface at all potentials studied and that the pztc was much more negative in $[\mathrm{dema}]\left[\mathrm{Tf}_{2} \mathrm{~N}\right]$ than in the other PILs. It is likely that this binding of the $\left[\mathrm{Tf}_{2} \mathrm{~N}\right]^{-}$ions to the Pt surface is responsible for the features observed in the surface electrochemistry of Pt in the blank PILs and during the CO oxidation. Appreciable hydrogen adsorption did not occur during potential cycling in $[\operatorname{dema}]\left[\mathrm{Tf}_{2} \mathrm{~N}\right]$ as the $\left[\mathrm{Tf}_{2} \mathrm{~N}\right]^{-}$ ions occupied $\mathrm{H}$ adsorption sites on the Pt surface (Figure 2C). Blockage of $\mathrm{H}$ adsorption sites by $\left[\mathrm{Tf}_{2} \mathrm{~N}\right]^{-}$ions during $\mathrm{CO}$ deposition meant that early onset oxidation of $\mathrm{CO}$ did not occur in $[$ dema $]\left[\mathrm{Tf}_{2} \mathrm{~N}\right]$ (Figure 1C). This is not the first time that strong adsorption of $\left[\mathrm{Tf}_{2} \mathrm{~N}\right]^{-}$ anions to Pt surfaces has been proposed; indeed, Hanc-Scherer and co-workers very recently suggested that strong adsorption of $\left[\mathrm{Tf}_{2} \mathrm{~N}\right]^{-}$anions to Pt surfaces may be responsible for sluggishness of $\mathrm{CO}$ oxidation in aprotic $\left[\mathrm{Tf}_{2} \mathrm{~N}\right]^{-}$-based ionic liquids when compared to $\left[\mathrm{BF}_{4}\right]^{-}-$ based liquids. ${ }^{49}$ We also note that the same authors speculated that the hydrophobic nature of the $\left[\mathrm{Tf}_{2} \mathrm{~N}\right]$ - ionic liquid may also be responsible the differing rates of reaction as less water may be available for the nucleation of surface oxide ions in the $\left[\mathrm{Tf}_{2} \mathrm{~N}\right]^{-}$-based liquid. In our work, the bulk CO oxidation peak potential was similar in each PIL (Figure 1), so any differences in water activities in the PILs are not reflected in a difference in the bulk CO oxidation potentials. In addition, the water concentrations of the PILs were comparable so it does appear that binding of the $\left[\mathrm{Tf}_{2} \mathrm{~N}\right]^{-}$anion to the Pt surface, rather than significant differences in water activities, was responsible for the differing $\mathrm{CO}$ electrochemistry in the $[\mathrm{TfO}]^{-}$- and $\left[\mathrm{Tf}_{2} \mathrm{~N}\right]^{-}$-based liquids.

The effects of a strong interaction between the $\left[\mathrm{Tf}_{2} \mathrm{~N}\right]^{-}$ion and the Pt surface may also be evident in electrocatalysis of the ORR at Pt in the PILs. For example, Figure 6 shows the polarisation curves recorded in $\mathrm{O}_{2}$-saturated [dema] $[\mathrm{TfO}]$ and $[\mathrm{dema}]\left[\mathrm{Tf}_{2} \mathrm{~N}\right]$ at $45{ }^{\circ} \mathrm{C}$. In [dema][TfO], the ORR current started to flow at $0.7 \mathrm{~V}$ and reached a diffusion-limited value 
at $0.4 \mathrm{~V}$ (Figure 6A), in agreement with previous reports on $\mathrm{O}_{2}$ electrochemistry at $\mathrm{Pt}$ in $[\mathrm{dema}][\mathrm{TfO}] .^{41,64}$ In contrast, the ORR onset potential in $[\mathrm{dema}]\left[\mathrm{Tf}_{2} \mathrm{~N}\right]$ was approximately $-0.2 \mathrm{~V}$ and the current due to the ORR overlapped with that due to $\mathrm{H}_{2}$ evolution. A large difference in onset potentials for the ORR in [dema][TfO] and [dema] $\left[\mathrm{Tf}_{2} \mathrm{~N}\right]$ has been observed previously ${ }^{29}$ and it has been suggested that differences in ORR rates in different PILs can be attributed to differences in proton availability in various PILs. Specifically, it has been proposed by Watanabe and co-workers that the optimum PIL is one with a cation that
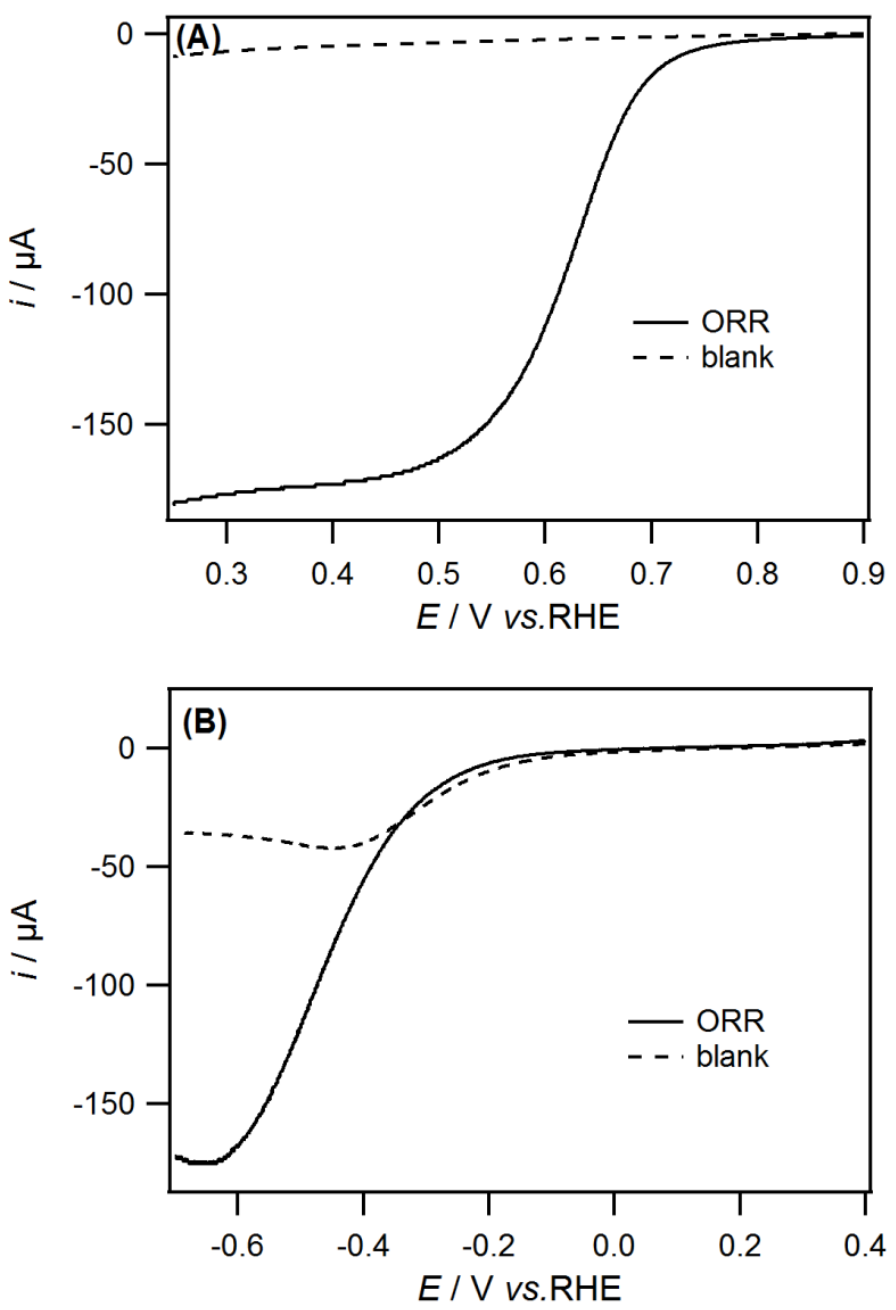

Figure 6. RDE voltammograms obtained at a $5 \mathrm{~mm}$ diameter Pt disk at $200 \mathrm{rpm}, 50 \mathrm{mV} \mathrm{s}$ and $45{ }^{\circ} \mathrm{C}$ in (A) $\mathrm{O}_{2}$-saturated [dema] [TfO] as the potential was swept from $0.9 \mathrm{~V}$ to $0.2 \mathrm{~V}$, and $(\mathrm{B}) \mathrm{O}_{2}$-saturated [dema] $\left[\mathrm{Tf}_{2} \mathrm{~N}\right]$ as the potential was swept from $0.4 \mathrm{~V}$ to $-0.65 \mathrm{~V}$. 
readily releases protons and also behaves as a strong conjugate acid and they drew a correlation between the measured open circuit potential (OCP) for a PIL-based $\mathrm{H}_{2} / \mathrm{O}_{2}$ fuel cell at $150{ }^{\circ} \mathrm{C}$ and $\Delta \mathrm{p} K_{\mathrm{a}}$ of the PIL. ${ }^{65}$ However, while proton availability no doubt plays a role during the ORR in PILs, this analysis does not take into account the effects of the electrode/PIL interfacial structure on electrocatalysis. As discussed in the introduction section, it is well known that strong adsorption of ions from aqueous electrolytes affects the rate of the ORR ${ }^{13,16,17}$ and we believe that such effects also play a role during the ORR in PILs. In this particular case, we believe that adsorption of spectator $\left[\mathrm{Tf}_{2} \mathrm{~N}\right]^{-}$ions onto the $\mathrm{Pt}$ surface may contribute to the high overpotential for the ORR in $[\mathrm{dema}]\left[\mathrm{Tf}_{2} \mathrm{~N}\right]$ relative to that in the $[\mathrm{TfO}]^{-}$-based liquids. We also note that such an effect has been proposed previously by Munakata and co-workers, who used in-situ FT-IR spectroscopy to study adsorption of the $\left[\mathrm{Tf}_{2} \mathrm{~N}\right]^{-}$ion from PILs onto Pt surfaces and correlated the strength of ion adsorption and the rate of the ORR. ${ }^{66}$

Given the important role that ion adsorption appears to play during electrocatalysis in ionic liquids, it will be interesting to explore the structure sensitivity of such processes and the impact of such phenomena on electrocatalysis. Interestingly, Hanc-Scherer and coworkers' recent work ${ }^{49}$ indicates that the rate of the $\mathrm{CO}$ oxidation reaction at $\mathrm{Pt}$ in aprotic ionic liquids depends on the crystallographic orientation of the electrode surface. Extension of such experimental methods to the analysis of ion adsorption and electrocatalysis at the interface between well-defined electrode surfaces and protic ionic liquids may not only reveal new insights into electrocatalysis but it may also allow us to design new electrocatalyst systems for use in these ionic liquid electrolytes. 


\section{Conclusions}

The effects of ion adsorption on electrocatalytic reactions in a series of protic ionic liquids have been studied. In the ionic liquids diethylmethylammonium trifluoromethanesulfonate, [dema][TfO], and dimethylethylammonium trifluoromethanesulfonate, [dmea][TfO], adsorption of a monolayer of hydrogen onto Pt can occur during potential cycling. In addition, a pre-peak is observed during $\mathrm{CO}$ oxidation at $\mathrm{Pt}$ in these ionic liquids. However, in the presence of the bis(trifluoromethanesulfonyl)imide, $\left[\mathrm{Tf}_{2} \mathrm{~N}\right]^{-}$, anion, hydrogen adsorption is suppressed during potential cycling in the blank liquid and no prepeak is observed during $\mathrm{CO}$ oxidation. Our data suggest that adsorbed hydrogen plays a role in early-onset $\mathrm{CO}$ oxidation in the PILs, as is the case during electrocatalysis in aqueous electrolytes. The interaction between the Pt surfaces and $\mathrm{CO}$ was also exploited to measure the potential of zero charge in the ionic liquids. These "CO-displacement" measurements, which have not been used in ionic liquids previously, indicate that the $\left[\mathrm{Tf}_{2} \mathrm{~N}\right]^{-}$anion remains adsorbed onto the Pt surface, even at relatively low potentials, and this interaction appears to be responsible for hindering both hydrogen adsorption and early-onset $\mathrm{CO}$ oxidation in [dema][Tf $\left.f_{2} \mathrm{~N}\right]$. Analysis of electrocatalytic $\mathrm{O}_{2}$ reduction data also reveals that $\mathrm{O}_{2}$ reduction is much slower in $[$ dema $]\left[\mathrm{Tf}_{2} \mathrm{~N}\right]$ than in the $[\mathrm{TfO}]^{-}$-containing liquids and we propose that this difference may also be attributable, at least in part, to blocking of catalytic sites by adsorbed $\left[\mathrm{Tf}_{2} \mathrm{~N}\right]^{-}$ions. In summary, the results described here indicate that the adsorption of ions onto electrode surfaces can play very significant roles during electrocatalytic processes in ionic liquids. Given the wide range of ionic liquids that are available, as well as their "tuneability", we anticipate that extension of the methods and analyses described here to novel electrode and electrolyte systems will yield new insights into electrochemistry in ionic liquids and even to the development of new electrocatalysts designed specifically for use in ionic liquids. Future work will focus on such opportunities. 


\section{Acknowledgements}

We thank the Leverhulme Trust for funding (Research Project Grant RPG-2012-510) and Prof. Peter Licence for allowing us access to facilities for synthesizing ionic liquids.

\section{References}

(1) Greeley, J.; Marković, N. M. The Road from Animal Electricity to Green Energy: Combining Experiment and Theory in Electrocatalysis. Energy Environ. Sci. 2012, 5, 9246-9256.

(2) Tripkovic, D. V.; Strmenik, D.; van der Vliet, D.; Stamenkovic, V.; Marković, N. M. The Role of Anions in Surface Electrochemistry. Faraday Discuss. 2008, 140, 25-40.

(3) Stamenkovic, V. R.; Mun, B. S.; Arenz, M.; Mayrhofer, K. J. J.; Lucas, C. A.; Wang, G. F.; Ross, P. N.; Marković, N. M. Trends in Electrocatalysis on Extended and Nanoscale Pt-Bimetallic Alloy Surfaces. Nat. Mater. 2007, 6, 241-247.

(4) Nørskov, J. K.; Rossmeisl, J.; Logadottir, A.; Lindqvist, L.; Kitchin, J. R.; Bligaard, T.; Jonsson, H. Origin of the Overpotential for Oxygen Reduction at a Fuel-Cell Cathode. J. Phys. Chem. B 2004, 108, 17886-17892.

(5) Zhou, W. P.; Yang, X. F.; Vukmirovic, M. B.; Koel, B. E.; Jiao, J.; Peng, G. W.; Mavrikakis, M.; Adzic, R. R. Improving Electrocatalysts for $\mathrm{O}_{2}$ Reduction by FineTuning the Pt-Support Interaction: Pt Monolayer on the Surfaces of a $\mathrm{Pd}_{3} \mathrm{Fe}(111)$ SingleCrystal Alloy. J. Am. Chem. Soc. 2009, 131, 12755-12762.

(6) Climent, V.; Feliu, J. M. Thirty Years of Platinum Single Crystal Electrochemistry. J. Solid State Electrochem. 2011, 15, 1297-1315.

(7) Sheng, W. C.; Chen, S.; Vescovo, E.; Shao-Horn, Y. Size Influence on the Oxygen Reduction Reaction Activity and Instability of Supported Pt Nanoparticles. J. Electrochem. Soc. 2012, 159, B96-B103. 
(8) Viswanathan, V.; Hansen, H. A.; Rossmeisl, J.; Nørskov, J. K. Universality in Oxygen Reduction Electrocatalysis on Metal Surfaces. ACS Catal. 2012, 2, 1654-1660.

(9) Strmcnik, D.; Kodama, K.; van der Vliet, D.; Greeley, J.; Stamenkovic, V. R.; Markovic, N. M. The Role of Non-Covalent Interactions in Electrocatalytic Fuel-Cell Reactions on Platinum. Nat. Chem. 2009, 1, 466-472.

(10) Marković, N. M.; Gasteiger, H. A.; Ross, P. N. Oxygen Reduction on Platinum Low-Index Single Crystal Surfaces in Sulfuric Acid Solution - Rotating Ring-Pt(hkl) Disk Studies. J. Phys. Chem. 1995, 99, 3411-3415.

(11) Stamenkovic, V.; Marković, N. M.; Ross, P. N. Structure-Relationships in Electrocatalysis: Oxygen Reduction and Hydrogen Oxidation Reactions on $\operatorname{Pt}(111)$ and $\operatorname{Pt}(100)$ in Solutions containing Chloride Ions. J. Electroanal. Chem. 2001, 500, 44-51.

(12) He, Q.; Yang, X.; Chen, W.; Mukerjee, S.; Koel, B.; Chen, S. Influence of Phosphate Anion Adsorption on the Kinetics of Oxygen Electroreduction on Low Index Pt(hkl) Single Crystals. Phys. Chem. Chem. Phys. 2010, 12, 12544-12555.

(13) Marković, N. M.; Ross, P. N. Surface Science Studies of Model Fuel Cell Electrocatalysts. Surf. Sci. Rep. 2002, 45, 121-229.

(14) Wang, C.; van der Vliet, D.; Chang, K.-C.; You, H.; Strmcnik, D.; Schlueter, J.

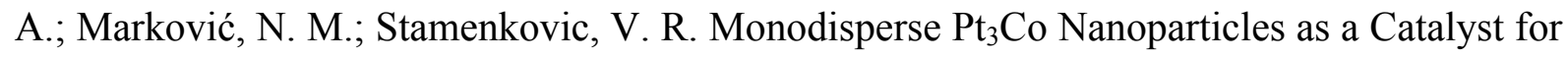
the Oxygen Reduction Reaction: Size-Dependent Activity. J. Phys. Chem. C 2009, 113, 19365-19368.

(15) van der Vliet, D. F.; Wang, C.; Tripkovic, D.; Strmcnik, D.; Zhang, X. F.; Debe, M. K.; Atanasoski, R. T.; Markovic, N. M.; Stamenkovic, V. R. Mesostructured Thin Films as Electrocatalysts with Tunable Composition and Surface Morphology. Nat. Mater. 2012, 11, 1051-1058. 
(16) Stamenkovic, V. R.; Fowler, B.; Mun, B. S.; Wang, G. F.; Ross, P. N.; Lucas, C. A.; Marković, N. M. Improved Oxygen Reduction Activity on $\mathrm{Pt}_{3} \mathrm{Ni}(111)$ via Increased Surface Site Availability. Science 2007, 315, 493-497.

(17) Stamenkovic, V.; Mun, B. S.; Mayrhofer, K. J. J.; Ross, P. N.; Marković, N. M.; Rossmeisl, J.; Greeley, J.; Nørskov, J. K. Changing the Activity of Electrocatalysts for Oxygen Reduction by Tuning the Surface Electronic Structure. Angew. Chem. Int. Ed. 2006, $45,2897-2901$.

(18) Wasserscheid, P.; Welton, T., Eds. Ionic Liquids in Synthesis; 2nd ed.; WileyVCH: Weinheim, 2008.

(19) Greaves, T. L.; Drummond, C. J. Protic Ionic Liquids: Properties and Applications. Chem. Rev. 2008, 108, 206-237.

(20) Welton, T. Room-Temperature Ionic Liquids. Solvents for Synthesis and Catalysis. Chem. Rev. 1999, 99, 2071-2083.

(21) Walsh, D. A.; Lovelock, K. R. J.; Licence, P. Ultramicroelectrode Voltammetry and Scanning Electrochemical Microscopy in Room-Temperature Ionic Liquid Electrolytes. Chem. Soc. Rev. 2010, 39, 4185-4194.

(22) Lovelock, K. R. J.; Ejigu, A.; Loh, S. F.; Men, S.; Licence, P.; Walsh, D. A. On the Diffusion of Ferrocenemethanol in Room-Temperature Ionic Liquids: An Electrochemical Study. Phys. Chem. Chem. Phys. 2011, 13, 10155-10164.

(23) Belding, S. R.; Rees, N. V.; Aldous, L.; Hardacre, C.; Compton, R. G. Behavior of the Heterogeneous Electron-Transfer Rate Constants of Arenes and Substituted Anthracenes in Room-Temperature Ionic Liquids. J. Phys. Chem. C 2008, 112, 1650-1657.

(24) Zhao, C.; Burrell, G.; Torriero, A. A. J.; Separovic, F.; Dunlop, N. F.; MacFarlane, D. R.; Bond, A. M. Electrochemistry of Room Temperature Protic Ionic Liquids. J. Phys. Chem. B 2008, 112, 6923-6936. 
(25) Silvester, D. S.; Compton, R. G. Electrochemistry in Room Temperature Ionic Liquids: A Review and Some Possible Applications. Z. Phys. Chem. 2006, 220, 1247-1274.

(26) Menne, S.; Pires, J.; Anouti, M.; Balducci, A. Protic Ionic Liquids as Electrolytes for Lithium-Ion Batteries. Electrochem. Commun. 2013, 31, 39-41.

(27) Tsunashima, K.; Yonekawa, F.; Sugiya, M. Lithium Secondary Batteries Using a Lithium Nickelate-Based Cathode and Phosphonium Ionic Liquid Electrolytes. Electrochem. Solid State Lett. 2009, 12, A54-A57.

(28) Armand, M.; Endres, F.; MacFarlane, D. R.; Ohno, H.; Scrosati, B. IonicLiquid Materials for the Electrochemical Challenges of the Future. Nat. Mater. 2009, 8, 621629.

(29) Lee, S. Y.; Ogawa, A.; Kanno, M.; Nakamoto, H.; Yasuda, T.; Watanabe, M. Nonhumidified Intermediate Temperature Fuel Cells Using Protic Ionic Liquids. J. Am. Chem. Soc. 2010, 132, 9764-9773.

(30) Belieres, J.-P.; Gervasio, D.; Angell, C. A. Binary Inorganic Salt Mixtures as High Conductivity Liquid Electrolytes for $>100{ }^{\circ} \mathrm{C}$ Fuel Cells. Chem. Commun. 2006, 47994801.

(31) Wang, P.; Zakeeruddin, S. M.; Moser, J.-E.; Grätzel, M. A New Ionic Liquid Electrolyte Enhances the Conversion Efficiency of Dye-Sensitized Solar Cells. J. Phys. Chem. B 2003, 107, 13280-13285.

(32) Lewandowski, A.; Galinski, M. Carbon-Ionic Liquid Double-Layer Capacitors. J. Phys. Chem. Solids 2004, 65, 281-286.

(33) Islam, M. M.; Alam, M. T.; Ohsaka, T. Electrical Double-Layer Structure in Ionic Liquids: A Corroboration of the Theoretical Model by Experimental Results. J. Phys. Chem. C 2008, 112, 16568-16574. 
(34) Baldelli, S. Surface Structure at the Ionic Liquid-Electrified Metal Interface. Acc. Chem. Res. 2008, 41, 421-431.

(35) Aliaga, C.; Santos, C. S.; Baldelli, S. Surface Chemistry of Room-Temperature Ionic Liquids. Phys. Chem. Chem. Phys. 2007, 9, 3683-3700.

(36) Nakamoto, H.; Watanabe, M. Brønsted Acid-Base Ionic Liquids for Fuel Cell Electrolytes. Chem. Commun. 2007, 2539-2541.

(37) Kucernak, A. R.; Offer, G. J. The Role of Adsorbed Hydroxyl Species in the Electrocatalytic Carbon Monoxide Oxidation Reaction on Platinum. Phys. Chem. Chem. Phys. 2008, 10, 3699-3711.

(38) Alvarez, B.; Climent, V.; Feliu, J. M.; Aldaz, A. Determination of Different Local Potentials of Zero Charge of a Pd-Au(111) Heterogeneous Surface. Electrochem. Commun. 2000, 2, 427-430.

(39) Gomez, R.; Climent, V.; Feliu, J. M.; Weaver, M. J. Dependence of the Potential of Zero Charge of Stepped Platinum(111) Electrodes on the Oriented Step-Edge Density: Electrochemical Implications and Comparison with Work Function Behavior. J. Phys. Chem. B 2000, 104, 597-605.

(40) Mayrhofer, K. J. J.; Blizanac, B. B.; Arenz, M.; Stamenkovic, V. R.; Ross, P. N.; Marković, N. M. The Impact of Geometric and Surface Electronic Properties of PtCatalysts on the Particle Size Effect in Electrocatalysis. J. Phys. Chem. B 2005, 109, 1443314440.

(41) Johnson, L.; Ejigu, A.; Licence, P.; Walsh, D. A. Hydrogen Oxidation and Oxygen Reduction in Protic Ionic Liquids. J. Phys. Chem. C 2012, 116, 18048-18056.

(42) Walsh, D. A.; Ejigu, A.; Muhammad, S.; Licence, P. The Formation and Role of Oxide Layers on Pt during Hydrazine Oxidation in Protic Ionic Liquids. ChemElectroChem 2014, 1, 281-288. 
(43) Bautista-Martinez, J. A.; Tang, L.; Belieres, J. P.; Zeller, R.; Angell, C. A.; Friesen, C. Hydrogen Redox in Protic Ionic Liquids and a Direct Measurement of Proton Thermodynamics. J. Phys. Chem. C 2009, 113, 12586-12593.

(44) Tremblay, J.; Nguyen, N. L.; Rochefort, D. Hydrogen Absorption by a Palladium Electrode from a Protic Ionic Liquid at Temperatures exceeding $100{ }^{\circ} \mathrm{C}$. Electrochem. Commun. 2013, 34, 102-104.

(45) Bard, A. J.; Faulkner, L. R. In Electrochemical Methods: Fundamentals and Applications; Second ed.; John Wiley \& Sons: 2001, p 339.

(46) Trasatti, S.; Petrii, O. A. Real Surface-Area Measurements in Electrochemistry. Pure Appl. Chem. 1991, 63, 711-734.

(47) Meng, Y.; Norman, S.; Hardacre, C.; Compton, R. G. The Electroreduction of Benzoic Acid: Voltammetric Observation of Adsorbed Hydrogen at a Platinum Microelectrode in Room Temperature Ionic Liquids. Phys. Chem. Chem. Phys. 2013, 15, 2031-2036.

(48) Ejigu, A.; Johnson, L.; Licence, P.; Walsh, D. A. Electrocatalytic Oxidation of Methanol and Carbon Monoxide at Platinum in Protic Ionic Liquids. Electrochem. Commun. 2012, 23, 122-124.

(49) Hanc-Scherer, F. A.; Sanchez-Sanchez, C. M.; Ilea, P.; Herrero, E. SurfaceSensitive Electrooxidation of Carbon Monoxide in Room Temperature Ionic Liquids. ACS Catal. 2013, 3, 2935-2938.

(50) Arenz, M.; Mayrhofer, K. J. J.; Stamenkovic, V.; Blizanac, B. B.; Tomoyuki, T.; Ross, P. N.; Marković, N. M. The Effect of the Particle Size on the Kinetics of CO Electrooxidation on High Surface Area Pt Catalysts. J. Am. Chem. Soc. 2005, 127, 6819-6829. 
(51) López-Cudero, A.; Cuesta, A.; Gutiérrez, C. Potential Dependence of the Saturation CO Coverage of Pt Electrodes: The Origin of the Pre-Peak in CO-Stripping Voltammograms. Part 1: Pt(111). J. Electroanal. Chem. 2005, 579, 1-12.

(52) Marković, N. M.; Lucas, C. A.; Grgur, B. N.; Ross, P. N. Surface Electrochemistry of $\mathrm{CO}$ and $\mathrm{H}_{2} / \mathrm{CO}$ Mixtures at $\mathrm{Pt}(100)$ Interface: Electrode Kinetics and Interfacial Structures. J. Phys. Chem. B 1999, 103, 9616-9623.

(53) Mayrhofer, K. J. J.; Arenz, M.; Blizanac, B. B.; Stamenkovic, V.; Ross, P. N.; Marković, N. M. CO Surface Electrochemistry on Pt-Nanoparticles: A Selective Review. Electrochim. Acta 2005, 50, 5144-5154.

(54) Wee, J. H.; Lee, K. Y. Overview of the Development of CO-Tolerant Anode Electrocatalysts for Proton-Exchange Membrane Fuel Cells. J. Power Sources 2006, 157, $128-135$

(55) Lauw, Y.; Horne, M. D.; Rodopoulos, T.; Nelson, A.; Leermakers, F. A. M. Electrical Double-Layer Capacitance in Room Temperature Ionic Liquids: Ion-Size and Specific Adsorption Effects. J. Phys. Chem. B 2010, 114, 11149-11154.

(56) Kornyshev, A. A. Double-Layer in Ionic Liquids: Paradigm Change? J. Phys. Chem. B 2007, 111, 5545-5557.

(57) Lockett, V.; Sedev, R.; Ralston, J.; Horne, M.; Rodopoulos, T. Differential Capacitance of the Electrical Double Layer in Imidazolium-Based Ionic Liquids: Influence of Potential, Cation Size, and Temperature. J. Phys. Chem. C 2008, 112, 7486-7495.

(58) Islam, M. M.; Alam, M. T.; Okajima, T.; Ohsaka, T. Electrical Double Layer Structure in Ionic Liquids: An Understanding of the Unusual Capacitance-Potential Curve at a Nonmetallic Electrode. J. Phys. Chem. C 2009, 113, 3386-3389. 
(59) Fedorov, M. V.; Kornyshev, A. A. Ionic Liquid Near a Charged Wall: Structure and Capacitance of Electrical Double Layer. J. Phys. Chem. B 2008, 112, 1186811872.

(60) Fedorov, M. V.; Kornyshev, A. A. Towards Understanding the Structure and Capacitance of Electrical Double Layer in Ionic Liquids. Electrochim. Acta 2008, 53, 68356840.

(61) Frumkin, A. N.; Petrii, O. A. Potentials of Zero Total and Zero Free Charge of Platinum Group Metals. Electrochim. Acta 1975, 20, 347-359.

(62) Weaver, M. J. Potentials of Zero Charge for Platinum(111)-Aqueous Interfaces: A Combined Assessment from In-Situ and Ultrahigh-Vacuum Measurements. Langmuir 1998, 14, 3932-3936.

(63) Chen, Q.-S.; Solla-Gullon, J.; Sun, S.-G.; Feliu, J. M. The Potential of Zero Total Charge of Pt Nanoparticles and Polycrystalline Electrodes with Different Surface Structure: The Role of Anion Adsorption in Fundamental Electrocatalysis. Electrochim. Acta 2010, 55, 7982-7994.

(64) Walsh, D. A.; Ejigu, A.; Smith, J.; Licence, P. Kinetics and Mechanism of Oxygen Reduction in a Protic Ionic Liquid. Phys. Chem. Chem. Phys. 2013, 15, 7548-7554.

(65) Miran, M. S.; Yasuda, T.; Susan, M. A.; Dokko, K.; Watanabe, M. Electrochemical Properties of Protic Ionic Liquids: Correlation Between Open Circuit Potential for $\mathrm{H}_{2} / \mathrm{O}_{2}$ Cells under Non-Humidified Conditions and $\Delta \mathrm{p} K_{\mathrm{a}} . R S C A d v .2013,3$, 4141-4144.

(66) Munakata, H.; Tashita, T.; Haibara, M.; Kanamura, K. Synthesis of New Protic Ionic Liquids for Fuel Cells on the Basis of In-Situ FT-IR Measurements. ECS Trans. 2010, $33,463-469$. 


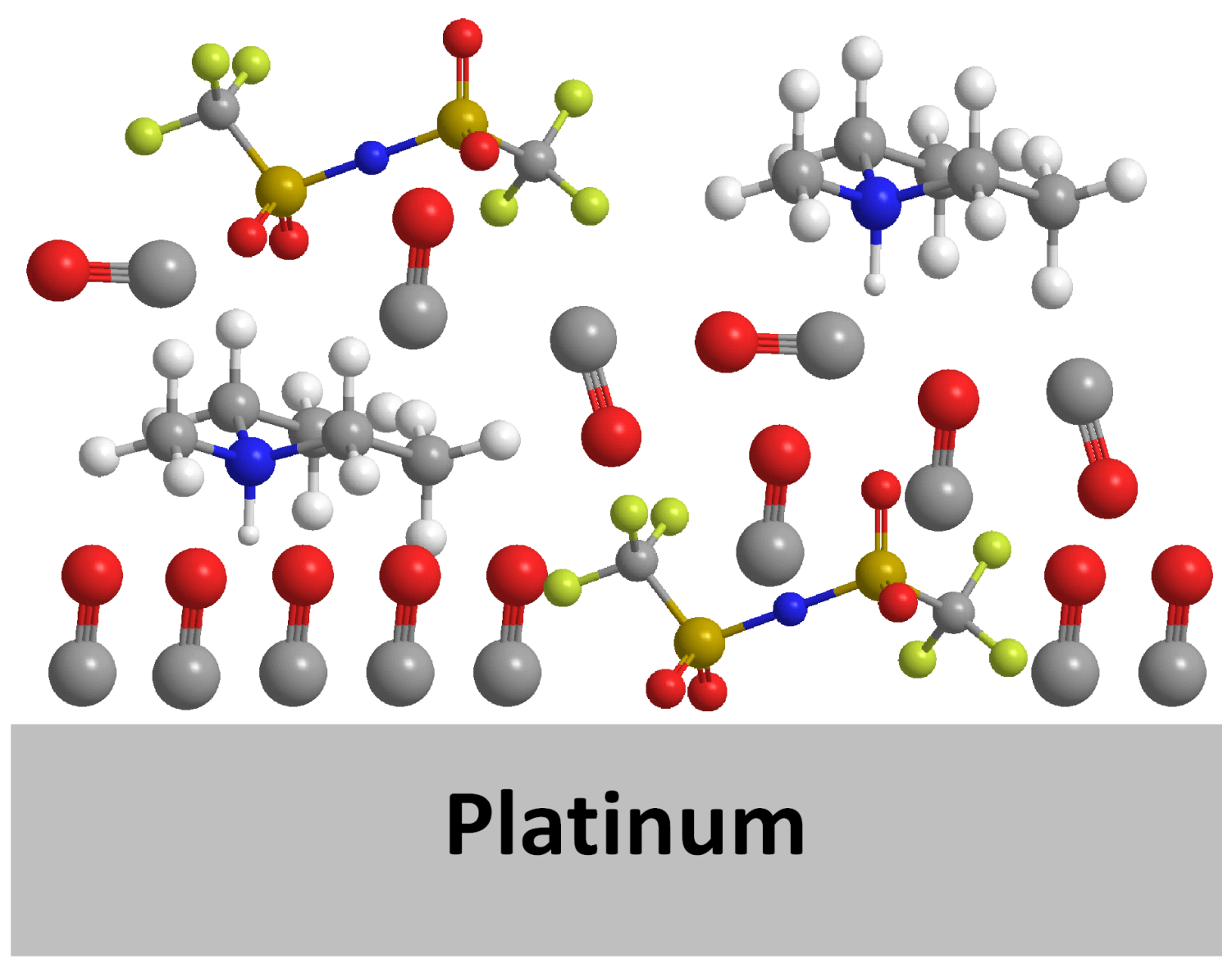

The effects of ion adsorption onto Pt electrodes during electrocatalysis of $\mathrm{CO}$ oxidation and oxygen reduction in protic ionic liquids are examined 